\title{
El Delito de Blanqueo de Capitales en contexto con el Derecho Positivo Panameño
}

\author{
Julia Elena Sáenz. \\ Universidad de Panamá \\ Facultad de Derecho y Ciencias Políticas \\ Departamento de Ciencias Penales y Criminológicas \\ E-mail: juliaelenasaenz@gmail.com
}

Sumario: Introducción. 1. Antecedentes. 2. Marco Conceptual. 3. Análisis Jurídico Penal. 4. Aspectos Procesales. 5. Legislación Bancaria. 6. Derecho Internacional. 7. Perfil Criminológico del Sujeto Activo en el Delito de Blanqueo de Capitales.8. Consideraciones Finales. Referencias Bibliográficas.

\section{RESUMEN}

El blanqueo de capitales es un delito de carácter transnacional que responde a necesidades a nivel nacional y de la comunidad internacional, de la cual formamos parte, por combatir todo aquello que pueda afectar el orden económico. De tal manera, que los Estados diseñen estrategias de carácter jurídico, político, social y económico, que nos permita combatir con esta forma de delincuencia circunstancial y estructural que corroe los cimientos de la sociedad panameña.

Además, tenemos que esta es una figura delictiva que requiere de la existencia de un delito o evidencias precedentes, cuyo resultado ilícito requiere ser convertido en lícito. Es decir, que todo tipo de activos, valores o bienes que se obtienen producto de la realización de ilícitos, que han sido previamente tipificados como tal en la norma penal, sean convertidos en lícitos a través de su empleo en actividades comerciales y bancarias que cumplan con los parámetros legalmente establecidos.

\section{Palabras Claves}

Delito, blanqueo de capitales, lavado de activos, delito transnacional, delincuencia organizada.

\begin{abstract}
Money laundering is a crime of transnational nature which responds to needs at the national level and the international community, of which we are part, to combat everything that may affect the economic order. In such a way that States design legal, political, social and economic strategies, allow us to combat this form of crime, situational and structural that mail the foundations of Panamanian society. In addition, we have that this is a criminal figure who requires the existence of a crime or previous evidence, whose illicit result required to be converted into lawful. I.e., that all kinds of assets, securities or goods obtained carrying out illicit product, that have been previously defined as such in the penal norm, are converted into lawful through its use in commercial and banking activities that meet with the legally established parameters.
\end{abstract}

Keywords: Crime, money laundering, washing of assets, transnational crime, organized crime. 


\section{Introducción}

El delito de blanqueo de capitales es una figura delictiva que aunque podemos encontrar sus orígenes en tiempos pasados, referentes a la época de la conquista, este ha tenido un despunte en el siglo xx y, por ende, en la actualidad. Sin embargo, a lo largo del tiempo se ha ido perfeccionando, convirtiéndose en una figura delictiva muy difícil de combatir debido a que la misma implica el surgimiento y proliferación de redes de poder que actúan tanto a nivel nacional como internacional y, por consiguiente, hace de este tipo de hechos ilícitos muy difícil de erradicar. Sin embargo, consideramos necesario atender principalmente las causas que lo originan para poder combatirle. Es por ello, que consideramos necesario ahondar un poco más en cuáles son las necesidades reales a nivel de país y diseñar en base a ellas estrategias de desarrollo y protección a nuestro orden social principalmente, y con ello al orden económico de país.

\section{Antecedentes}

Para tener una mejor comprensión del delito de blanqueo de capitales en el contexto de la legislación penal panameña, es necesario entender desde cuándo está tipificada esta figura delictiva en Panamá y, por ende, es necesario saber que la vida republicana panameña empieza el 3 de noviembre de 1903 y con ella el inicio de la necesidad de una codificación propia. Siendo esto así, tenemos que en Panamá, hemos tenido cuatro códigos penales: 1916, 1922, 1982 y el de 2007, que es el vigente actualmente. Sin embargo, es a partir del código penal de 1982, que se incorpora esta figura delictiva mediante la modificación que sufre esta excerta legal a través de la Ley 41 de 2 de octubre de 2000, presente en la Gaceta Oficial \# 24,152 A.

Es en ese entonces cuando se tipifica en Panamá el delito de blanqueo de capitales en los artículos que van del 389 al 393, del código penal de 1982. Es importante conocer el contenido de dichos artículos para poder advertir los avances que se han hecho hasta la fecha. Siendo estos los siguientes:

a. Artículo 389: "El que reciba, deposite, negocie, convierta o transfiera dineros, títulos valores, bienes u otros recursos financieros, a sabiendas de que proceden de actividades relacionadas con el tráfico de drogas, estafa calificada, tráfico ilegal de armas, tráfico de personas, secuestro, extorsión, peculado, corrupción de servidores públicos, actos de terrorismo, robo o tráfico internacional de vehículos, previstas en la ley penal panameña, con el objeto de ocultar o encubrir su origen ilícito o ayudar a eludir las consecuencias jurídicas de tales hechos punibles, será sancionado con pena de 5 a 12 años de prisión y de 100 a 200 días-multa."

b. Artículo 390: "Será sancionado con la misma pena a que se refiere el artículo anterior:

1. El que a sabiendas oculte o encubra la real naturaleza, origen, ubicación, destino, propiedad o ayude a facilitar el beneficio de los dineros, títulos valores, bienes u otros recursos financieros, cuando éstos provengan o se hayan obtenido directa o indirectamente de alguna de las actividades ilícitas señaladas en el artículo 389 de este Código.

2. El que a sabiendas realice transacciones, por sí o por interpuesta persona natural o jurídica, en establecimientos bancarios, financieros, comerciales o de cualquier naturaleza, con dineros, títulos valores, bienes $\mathrm{u}$ otros recursos financieros 
procedentes de algunas de las actividades ilícitas previstas en el artículo 389 de este Código.

3. El que por sí o por interpuesta persona, a sabiendas, suministre a un establecimiento bancario, financiero, comercial o de cualquier otra naturaleza, información falsa para la apertura de cuentas o para la realización de transacciones con dineros, títulos valores, bienes u otros recursos financieros, cuando éstos provengan o se hayan obtenido de alguna de las actividades ilícitas señaladas en el artículo 389 de este Código."

c. Artículo 391: "El que a sabiendas se valga de su función, empleo, oficio o profesión para autorizar o permitir el delito de blanqueo de capitales, descrito en el artículo 389 de este Código, será sancionado con prisión de 3 a 8 años."

d. Artículo 392: "El que a sabiendas reciba o utilice dinero o cualquier recurso financiero proveniente de los delitos relacionados con el narcotráfico o con el blanqueo de capitales, para el financiamiento de campañas políticas o de cualquier naturaleza, será sancionado con prisión de 5 a 10 años e inhabilitación para el ejercicio de funciones públicas por igual término, después de cumplida la pena de prisión."

e. Artículo 393: "El servidor público que oculte, altere, sustraiga o destruya las evidencias o pruebas de los delitos relacionados con el narcotráfico o con el blanqueo de capitales, o procure la evasión de la persona aprehendida, detenida o sentenciada, o reciba dinero u otros beneficios con el fin de favorecer o perjudicar a alguna de las partes en el proceso, será sancionado con pena de 5 a 10 años de prisión e inhabilitación para ocupar cargos públicos hasta por10 años.”

Podemos observar que el delito de blanqueo de capitales ha evolucionado desde el momento en que se introdujo por primera vez, en Panamá, en el año 2000, ya que el radio de acción en cuanto al número de los delitos precedentes, en la actualidad, es mayor. Hoy día, contamos con mayor especificidad en cuanto a la descripción del mismo tipo penal, aunque la punibilidad sigue siendo la misma en lo referente a la pena de prisión; sin embargo, se eliminó sanción de días - multa y en algunas otras el mínimo de la pena de prisión ha aumentado.

En este mismo orden de ideas, hemos advertido que el sujeto activo del tipo básico en este delito era considerado exclusivamente a quien actuaba directamente pero, en cambio, actualmente se contempla a quien actúa tanto directa o indirectamente, esto quiere decir a través de otra persona. En cambio, con relación al sujeto activo específico, como es el caso del servidor público que se valga del ejercicio de su cargo para incurrir en la comisión de este tipo de delito, se mantiene igual. Sin embargo, en la actualidad se amplía el sujeto activo a todas aquellas personas que se valen de su profesión, empleo u oficio para incurrir en este tipo de figura delictiva.

Lo importante con los señalamientos expuestos anteriormente es que nuestra legislación penal ha tratado de evolucionar en atención a las necesidades de la sociedad panameña y de la comunidad internacional de la cual forma parte.

Ahora bien, tenemos que tomar en cuenta que el origen de este tipo de delito se encuentra en factores criminógenos de carácter externo, entre los cuales podemos mencionar principalmente, la situación económica precaria del individuo, misma que le orilla a buscar alternativas de vida al margen de la ley, la moral y las buenas costumbres. Además, aunado a esto se encuentran los movimientos migratorios puesto que a través de estos no solamente llegan los emigrantes con sus costumbres y tradiciones, sino también introducen al territorio, al cual emigran, las conductas ilícitas propias de sus países. 
De tal forma, que esto no es nuevo. Por ejemplo, es válido indicar que el principal antecedente del delito de blanqueo de capitales se encuentra en la Edad Media con la figura de los usureros (prestamistas) y los mercaderes. Luego, con el correr del tiempo, durante los siglos XVI y XVII tenemos a los famosos corsarios o piratas, quienes saqueaban la riqueza de los países que conforman el continente americano, entre ellos Panamá. Nosotros fuimos víctimas de hombres funestos como Francis Drake y Henry Morgan, quienes quemaron nuestras tierras y se llevaron nuestro oro. Este metal precioso era obtenido en forma ilícita y luego, con el amparo de los miembros de la realeza inglesa y española, era convertido en lícito, ya que parte de este oro se le entrega al rey y la otra parte le correspondía al pirata, como una forma de agradecerle el descubrimiento de nuevas tierras.

Sin embargo, el delito de lavado de activos o blanqueo de capitales tiene su despunte y perfeccionamiento en el siglo xx, principalmente en la década de los años veinte (20), en los Estados Unidos de Norteamérica, a través del desarrollo de las mafias, siendo uno de los principales capos de la época, el italiano - neoyorkino, Al Capone. Este sujeto fue en realidad el precursor del delito de blanqueo de capitales, ya que desarrolló la estructura comercial de dicha figura delictiva a través de la implementación del negocio de las lavanderías industriales. Este negocio consistía en que en locales comerciales instalaba un gran número de máquinas lavadoras de ropa para que la gente fuera a lavar su ropa sucia. Para esto, los clientes utilizaban una especie de monedas, que al introducirlas en las máquinas, éstas se ponían a funcionar. De esta manera era muy difícil determinar, por parte de la oficina tributaria la cantidad exacta de dinero que Capone obtenía del negocio de las lavanderías. Pero, este fue solamente el principio puesto que no solamente se lavaba el dinero proveniente de contrabando de bebidas alcohólicas, sino el obtenido de extorsiones, prostitución y tráfico de armas. Vemos entonces como a pesar de haber sido siempre un delito autónomo, ha requerido de la comisión de actos ilícitos precedentes puesto que es el producto de estos actos el utilizado para convertirlos en lícitos mediante su uso en actividades comerciales establecidas en atención a los parámetros que la ley contemplaba.

A pesar que en los Estados Unidos de Norteamérica se tiene como un antecedente del delito de blanqueo de capitales las prácticas delictivas de la mafia neoyorkina - italiana, es en 1982 cuando se implementa la denominación "money laundering", luego de la investigación que llevan a cabo agentes federales del gobierno en USA, a la ruta que llevan los dineros que introducen al sistema bancario estadounidense, narcotraficantes de cocaína colombiana.

En síntesis, el antecedente principal del delito de blanqueo de capitales lo constituye la necesidad que siente la comunidad internacional de resguardar sus fronteras y con ello, la economía de sus países y los bienes jurídicos de mayor trascendencia en la sociedad, como lo son: la vida, la integridad personal, el pudor y la libertad sexual, el orden económico y la humanidad.

\section{Marco Conceptual}

El delito de blanqueo de capitales también conocido como: lavado de activos; lavado de dinero; legitimación de ganancias ilícitas; legitimación de capitales, operaciones con recursos de procedencia ilícita; legitimación de capitales procedentes de narcotráfico; entre otros. Además, es un delito de carácter transnacional que afecta tanto los intereses económicos a nivel interno de un Estado, como a nivel de la comunidad internacional. En términos generales, implica un conjunto de actos idóneos que tienen como finalidad convertir dinero 
ilícito en dinero lícito. Es decir, el dinero o activos provenientes de la realización de delitos que han sido previamente establecidos por el ordenamiento jurídico, se invierte en negocios lícitos a través de los cuales se puedan justificar el ingreso o tenencia de determinada cantidad de dinero.

El tipo penal básico, del delito bajo estudio, está contemplado en el Código Penal Panameño, en el Libro II (Los Delitos), en el Título VII (Delitos contra el Orden Económico), Capítulo IV (Delitos de Blanqueo de Capitales), en el artículo 254, mismo que establece lo siguiente:

"Quien, personalmente o por interpuesta persona, reciba, deposite, negocie, transfiera o convierta dineros, títulos, valores, bienes u otros recursos financieros, previendo razonablemente que proceden de actividades relacionadas con el soborno internacional, los delitos contra el Derecho de Autor y Derechos Conexos, delitos contra los Derechos de la Propiedad Industrial, Tráfico Ilícito de Migrantes, Trata de Personas, tráfico de órganos, delitos contra la Personalidad Jurídica del Estado, delitos contra la Seguridad Jurídica de los Medios Electrónicos, estafa calificada, Robo, Delitos Financieros, Secuestro, Extorsión, homicidio por precio o recompensa, peculado, corrupción de servidores públicos, enriquecimiento injustificado, pornografía y corrupción de personas menores de edad, robo o tráfico internacional de vehículos, sus piezas y componentes, falsificación de documentos en general, omisión o falsedad de la declaración aduanera del viajero respecto a dineros, valores o documentos negociables, falsificación de moneda y otros valores, delitos contra el Patrimonio Histórico de la Nación, delitos contra la Seguridad Colectiva, Terrorismo y Financiamiento del Terrorismo, delitos relacionados con drogas, piratería, delincuencia organizada, asociación ilícita, pandillerismo, posesión y tráfico de armas y explosivos, apropiación y sustracción violenta de material ilícito, tráfico y receptación de cosas provenientes del delito, delitos de contrabando o defraudación aduanera, con el objeto de ocultar, encubrir o disimular su origen ilícito, o ayude a eludir las consecuencias jurídicas de tales hechos punibles, será sancionado con pena de cinco a doce años de prisión."

En atención a lo antes expuesto, podemos identificar los siguientes aspectos en el concepto de blanqueo de capitales:

a. El delito de blanqueo de capitales requiere para su conformación de la existencia de un delito precedente, determinante o subyacente. Es decir, requiere que se configuren actos ilícitos para que el resultado obtenido de estos, sea utilizado en la conformación del delito de blanqueo o lavado activos.

La Convención de las Naciones Unidas Contra la Delincuencia Organizada Transnacional, en su artículo 2, define, entre otros términos, el de delito determinante, de la siguiente manera: ... f) "Por "delito determinante" se entenderá todo delito del que se derive un producto que pueda pasar a constituir materia de un delito definido en el artículo 6 de la presente Convención; ...."

Tenemos entonces, que tal como expresamos en párrafos anteriores, si no se ha llevado a cabo un delito cuyo resultado o, lo que se derive de él, se utilice para la conformación de otro delito, no podríamos hablar del delito de blanqueo de capitales. Sin embargo, nosotros nos atrevemos a decir que en realidad se precisa la realización de conductas ilícitas, que si bien es cierto constan de una punibilidad presente en la norma penal, 
ellas per se no han sido penalizada, ya que no requiere necesariamente que las mismas hayan sido demostradas en un proceso penal. Dicho de otra manera, puede ser que toda la comunidad en la cual vive la Sra. X, sabe que ella vende cocaína; sin embargo, nunca se le ha realizado a su casa un allanamiento, ni tampoco se le ha seguido un proceso por venta de drogas. A pesar de todo esto, la Sra. X, financia proyectos que consisten en dar un capital semilla para su primer negocio a mujeres que han sido víctimas de violencia doméstica, han tenido que abandonar junto con sus hijos el domicilio conyugal y emprender una nueva vida con ellos. Una vez, presentado el proyecto la Sra. X entrega a la mujer la suma de $\mathrm{B} / 1,000 .{ }^{00}$ que deberá retornarle en un plazo de 20 meses.

En el ejemplo que acabamos de presentar se configura el delito de blanqueo de capitales. ¿Por qué? Simple y sencillamente, porque el dinero que las mujeres víctimas de violencia doméstica están invirtiendo en sus nuevos negocios proviene de la venta de drogas y está acción es un delito. Es decir, no importa que la Sra. X, no haya sido procesada por el delito de venta de drogas, ya que la conducta que realiza por sí sola constituye un ilícito.

b. Los delitos precedentes, determinantes o subyacentes del blanqueo de capitales están establecido en el tipo penal básico de esta figura delictiva. Es decir, no se consideran otros delitos que no sean los ya señalados en la norma penal. Además, estas figuras delictivas han sido establecidas luego de un profundo análisis a nivel internacional, ya que se considera que a través de su realización afectan bienes e intereses jurídicos dentro de un Estado y muy probablemente de la comunidad internacional.

c. Esta figura delictiva afecta los intereses materiales de la sociedad y por ende, vulnera el orden social del cual estos intereses forman parte. Es decir, al vulnerarse el sistema financiero del país, debido a que se abre una cuenta corriente con dinero proveniente del delito de peculado, se está afectando también la credibilidad del gobierno que conforma un Estado. Pero, además, se está afectando los intereses múltiples de la sociedad, como, por ejemplo: la moral, el patrimonio económico de los particulares, entre otras cosas.

d. Aunque se plantea el delito de delincuencia organizada, de manera independiente, como delito subyacente, consideramos que la consecución de todos los actos idóneos del delito de blanqueo de capitales constituyen la existencia de una delincuencia organizada. Es decir, para que se obtenga dinero o, cualquier clase de valores o bienes que hayan provenido de cualquiera de los delitos que nos presenta el tipo penal básico, del artículo 254 del código penal panameño, se hace necesario la existencia de una estructura organizacional delictiva a nivel nacional y, que es muy probable, para no decir seguro, que ésta a su vez tiene nexos con estructuras a nivel internacional, formando entonces redes de poder delictivo a nivel mundial.

e. El delito de blanqueo de capitales puede ser considerado, dependiendo del delito determinante, tanto circunstancial como estructural. Por ejemplo, en aquellos casos en que el delito subyacente es tráfico ilícito de migrantes, generalmente estaremos ante un blanqueo de capitales circunstancial, ya que es probable que en el país del cual sean oriundas las personas traficadas existan problemas como una guerra civil, un sistema de gobierno dictatorial en el cual no se respeten los derechos humanos, siendo alguna de estas situaciones emergentes las que han dado lugar a que las personas quieran salir 
abruptamente de sus países, convirtiéndose en presa fácil de la delincuencia. Esto por una parte, por otra, esta situación da origen a que otras personas, ideen nuevas formas delictivas que es probable no existían en sus países. Es en realidad de esta forman donde surgen los coyotes o personas que se encargan de introducir a un país, migrantes que no cumplen con los requisitos legales que el mismo establece.

En este mismo orden de ideas, tenemos que en aquellos casos en que el delito determinante sea como por ejemplo: el de corrupción de servidores públicos o, el delito de enriquecimiento injustificado, tenemos entonces que estamos ante un blanqueo de capitales estructural, ya que la credibilidad institucional ha fallado; se afectó en su totalidad el orden social de esa sociedad, se afectaron los intereses morales, religiosos y éticos de la misma.

Por consiguiente, el delito de blanqueo de capitales solamente puede ser analizado tomando en consideración su delito precedente.

\section{Análisis Jurídico Penal}

El delito de blanqueo de capitales está regulado en Panamá, a través de su Código Penal de 2007, en los artículos que van del 254 al 259, de la siguiente manera:

a. Tipicidad Objetiva: en cuanto al verbo tipo o conducta ilícita, objeto jurídico, bien jurídico tutelado, y los sujetos, se plantea lo siguiente:

1. Entre los diferentes verbos tipos o conductas ilícitas podemos mencionar los siguientes:

a. Recibir dineros, títulos, valores, bienes u otros recursos financieros, previendo razonablemente que proceden de actividades relacionadas con delitos que la ley haya determinado previamente, con la finalidad de ocultar, encubrir o disimular su origen ilícito, o para ayudar a eludir las consecuencias jurídicas de estos delitos. (art. 254 c. p.)

b. Depositar dinero, títulos, valores, bienes u otros recursos financieros, previendo razonablemente que proceden de actividades relacionadas con delitos que la ley haya determinado previamente, con la finalidad de ocultar, encubrir o disimular su origen ilícito, o para ayudar a eludir las consecuencias jurídicas de estos delitos. (art. 254 c .p.)

c. Negociar dinero, títulos, valores, bienes u otros recursos financieros, previendo razonablemente que proceden de actividades relacionadas con delitos que la ley haya determinado previamente, con la finalidad de ocultar, encubrir o disimular su origen ilícito, o para ayudar a eludir las consecuencias jurídicas de estos delitos. (art. 254 c. p.)

d. Transferir dinero, títulos, valores, bienes u otros recursos financieros, previendo razonablemente que proceden de actividades relacionadas con delitos que la ley haya determinado previamente, con la finalidad de ocultar, encubrir o disimular su origen ilícito, o para ayudar a eludir las consecuencias jurídicas de estos delitos. (art. 254 c. p.)

e. Convertir dinero, títulos, valores, bienes u otros recursos financieros, previendo razonablemente que proceden de actividades relacionadas con delitos que la ley haya determinado previamente, con la finalidad de ocultar, 
encubrir o disimular su origen ilícito, o para ayudar a eludir las consecuencias jurídicas de estos delitos. (art. 254 c. p.)

f. Ocultar el origen, la ubicación, el destino o la propiedad de dineros, bienes, títulos-valores u otros recursos financieros, cuando estos provengan o se hayan obtenido directa o indirectamente de alguna de las actividades ilícitas señaladas en el artículo 254 del código penal. (art. 255 c. p.)

g. Encubrir el origen, la ubicación, el destino o la propiedad de dineros, bienes, títulos-valores u otros recursos financieros, cuando estos provengan o se hayan obtenido directa o indirectamente de alguna de las actividades ilícitas señaladas en el artículo 254 del código penal. (art. 255 c. p.)

h. Impedir la determinación, la ubicación, el destino o la propiedad de dineros, bienes, títulos-valores u otros recursos financieros, cuando estos provengan o se hayan obtenido directa o indirectamente de alguna de las actividades ilícitas señaladas en el artículo 254 del código penal. (art. 255 c. p.)

i. Ayudar a asegurar el provecho de dineros, bienes, títulos-valores u otros recursos financieros, cuando estos provengan o se hayan obtenido directa o indirectamente de alguna de las actividades ilícitas señaladas en el artículo 254 del código penal. (art. 255 c. p.)

j. Realizar transacciones en establecimientos bancario, financiero, comercial o de cualquier otra naturaleza, con dinero, títulos - valores u otros recursos financieros procedentes de cualquiera de las actividades que establece el artículo 254 del código penal. (art. 255 c. p.)

k. Suministrar información falsa para lograr apertura de cuentas en cualquier establecimiento bancario, financiero o comercial, con relación a dineros, títulos - valores u otros recursos financieros procedentes de cualquiera de las actividades que establece el artículo 254 del código penal. (art. 255 c. p.)

1. Suministrar información falsa para lograr realizar cualquier clase de transacción con dineros, títulos - valores u otros recursos financieros procedentes de cualquiera de las actividades que establece el artículo 254 del código penal. (art. 255 c. p.)

$\mathrm{m}$. Recibir dinero o cualquier recurso financiero proveniente del blanqueo de capitales, para el financiamiento de campaña política o de cualquier otra naturaleza. (art. 256 c. p.)

n. Utilizar dinero o cualquier recurso financiero proveniente del blanqueo de capitales, para el financiamiento de campaña política o de cualquier otra naturaleza. (art. 256 c. p.)

o. Permitir el delito de blanqueo de capitales valiéndose de su empleo, oficio, función o profesión. (art. 257 c. p.)

p. Autorizar el delito de blanqueo de capitales valiéndose de su empleo, oficio, función o profesión. (art. 257 c. p.)

q. Ocultar evidencia o prueba de delito relacionado con blanqueo de capitales. (art. 258 c. p.)

r. Alterar evidencia o prueba de delito relacionado con blanqueo de capitales. (art.258 c. p.)

s. Sustraer evidencia o prueba de delito relacionado con blanqueo de capitales (art. 258 c. p.)

t. Destruir evidencia o prueba de delito relacionado con blanqueo de capitales (art. 258 c. p.)

u. Procurar la evasión de la persona aprehendida, detenida o sentenciada, por el delito de blanqueo de capitales. (art. 258 c. p.) 
v. Recibir dinero u otro beneficio con el fin de favorecer o perjudicar a laguna de las partes en un proceso de blanqueo de capitales. (art. 258 c. p.)

El Código Penal panameño, en su artículo 259 establece dos aspectos importantes, con respecto a la conducta ilícita, mismos que son los siguientes:

a. Con relación a los efectos de las transacciones de cualquier naturaleza, con respecto al delito de blanqueo de capitales, se tomará en cuenta que estas se realicen en la República de Panamá o desde la República de Panamá, o que el importe de dicha transacción se reciba en Panamá. Ejemplo: se envía a una cuenta bancaria en Panamá, dinero proveniente de cualquiera de las figuras delictivas determinantes del delito de blanqueo de capitales, para invertir en la construcción de un proyecto de vivienda dentro del territorio panameño.

b. Se presenta la definición legal del término transacciones, de la siguiente manera: “....., se entenderá, entre otras, como transacciones....., tales como depósito, compra de cheque de gerencia, tarjeta de crédito, débito o prepagada, giro, certificado de depósito, cheque de viajero o cualquier otro título - valor, transferencia y orden de pago, compra y venta de divisa, acción, bono y cualquier otro título o valor por cuenta del cliente,...."

2. Con relación al Objeto Jurídico indicaremos lo siguiente: está conformado por cualquier título - valor, entendiéndose por estos el dinero, bienes o cualquiera de los intereses materiales que conforman el orden económico del Estado.

3. En cuanto al Bien Jurídico es necesario indicar que: está constituido por el orden económico. Este a su vez, es el conjunto de intereses jurídicos que tiene la sociedad que es la base del Estado.

4. Con respecto a los sujetos planteamos los siguientes aspectos: tenemos en principio que el sujeto activo de este tipo de delito puede ser cualquier persona, tanto natural como jurídica, ya que con respecto a esta última se puede a través de diversas formas de sociedad jurídicas incurrir en el delito de blanqueo de capitales o lavado de activos. Sin embargo, tenemos también casos en que el agente o sujeto activo puede ser considerado como específico, como en aquellos casos en que la misma norma penal se refiere a servidores públicos, quienes haciendo uso de las funciones públicas que ejercen favorezcan el blanqueo de capitales.

Por último, tenemos la figura del sujeto pasivo, en el caso del blanqueo de capitales, es el orden económico del país y de la comunidad internacional. Es decir, cada vez que se incurre el delito de blanqueo de capitales, en Panamá o, en cualquier otro lugar, se afecta la situación económica compartida entre los diferentes países, ya que este tipo de acción ilícita vulnera aspectos de carácter financiero, político, transacciones mercantiles y comerciales, sistemas monetarios, desarrollo de empresas transnacionales, transferencia de tecnología, vulnera el derecho del mar, todo lo referente a intereses sociales (religión, moral, integridad física, la vida, integridad sexual, etc.).

c. Tipicidad Subjetiva: el delito bajo estudio solamente puede realizarse con intención. Es decir, la persona está en conocimiento de la procedencia del dinero, títulos, valores, bienes. Es muy difícil, que el sujeto activo o agente desconozca el origen de los activos que está manejando. 
Lo anterior se advierte del mismo texto de las diferentes normas jurídicas que contemplan el delito de blanqueo de capitales, como por ejemplo, tenemos:

1. Art. 254 c. p.: "Quien, personalmente o por interpuesta persona,...., con el objeto de ocultar, encubrir o disimular su origen ilícito, o ayude a eludir las consecuencias jurídicas de tales hechos punibles,....."

2. Art. 255 c. p.: “......1. Sin haber participado, pero a sabiendas de su procedencia, oculte, encubra o impida la terminación, el origen,... 2. Realice transacciones personalmente $o$ por interpuesta persona, natural 0 jurídica,...., 3. Personalmente o por interpuesta persona, natural o jurídica, suministre a otra...."

3. Art. 256 c. p.: "Quien, a sabiendas de su procedencia,...."

4. Art. 257 c. p.: "Quien, a sabiendas de su procedencia,...."

5. Art. 258 c. p.: "El servidor público que oculte,...."

De los textos legales citados en párrafos anteriores, podemos colegir que se presume el elemento del dolo en el comportamiento del agente o sujeto activo. Es decir, se entiende que el agente conocía la procedencia u origen de los activos, aunque no hubiese participado en la comisión del delito determinante o precedente. La intención o dolo del agente, queda manifiesta con el conocimiento de cómo se obtuvieron los activos o, de los antecedentes de la persona, natural o jurídica, con quien se está realizando la transacción comercial o financiera.

En este mismo orden de ideas, cabe señalar que el Código Penal panameño de 2007 y, por ende, el vigente, considera que todos los delitos que se encuentran en él tipificados son realizados con dolo salvo los casos en que el mismo tipo penal señale lo contrario, es decir, que indique se cometen por culpa. Así lo establece el artículo 26, de la excerta legal citada, bajo el tenor siguiente: "Para que una conducta sea considerada delito debe ser realizada con dolo, salvo los casos de culpa previstos por este Código...". De tal manera, que en vista, que el tipo penal del delito de blanqueo de capitales no contempla el hecho que alguna de estas acciones ilícitas hayan sido realizadas por culpa, se presume que el actuar del sujeto activo o agente, es en conciencia de lo que está haciendo y las implicaciones que conlleva su actuar.

d. Clase de Delito: El delito de blanqueo de capitales o lavado de activos, lo podemos clasificar de la siguiente manera:

1. Es material, ya que requiere el resultado criminoso del actuar del agente y la realización de un delito precedente, determinante o subyacente.

2. Es permanente, puesto que los efectos del mismo dejan una secuela o efectos que afectan a través del tiempo el orden económico de un país y, por ende, de la comunidad internacional al cual este pertenece.

3. Es un delito de comisión, pero en algunas ocasiones puede constituirse en forma de omisión impropia o comisión por omisión.

4. Es un delito complejo, ya que está conformado por más de dos verbos tipos.

5. Es plurisubsistente, puesto que requiere la realización de una multiplicidad de actos ilícitos idóneos, empezando por el de carácter precedente.

6. Se encuentra también dentro de la gama de los delitos plurisubjetivos, ya que se requiere de la participación de varias personas para la realización del mismo.

7. Este es un delito de carácter doloso puesto que se presume la intención del agente o sujeto activo. 


\section{Aspectos Procesales}

En el delito de blanqueo de capitales o lavado de activos el ejercicio de la acción penal es de carácter público, es decir, la ejercerá el Estado a través del Ministerio Público, una vez tenga conocimiento que este se está llevando a cabo y, en aquellos casos en que sea necesario, con el apoyo de los organismos policiales correspondientes (art. 111 c. p. p).

Además, tenemos que este es un delito que admite como medida cautelar de carácter personal, la detención preventiva o detención provisional, puesto que tiene como pena mínima cinco años de prisión (arts. 254 al 247 del c. p.), salvo el caso específico del manejo de la evidencia o prueba del delito, en el proceso, por parte del servidor público (art. 258 del c. p.), cuya pena mínima es de tres años.

Por otra parte, tenemos que la prescripción de la acción penal, en el delito de blanqueo de capitales, se da a los doce años, contados a partir de la realización delito, tal como lo señala el art. 116, numeral 1, del código procesal penal panameño.

Por último, es importante destacar que en cuanto a la acreditación del delito precedente, la jurisprudencia panameña establece que basta con que se compruebe la realización de cualesquiera de los verbos tipos que conforman el delito de blanqueo de capitales aunque no exista una sentencia en firme al respecto. Tal como se señala en la sentencia de 21 de septiembre de 2009, emitida por el Segundo Tribunal Superior de Justicia, del Primer Distrito Judicial, de la siguiente manera:

“......, no se logró demostrar que estuvieran vinculados al delito de Tráfico Internacional de Drogas, y aun cuando no se requiera que se pruebe la ejecución de los delitos predicados por el autor o autores del delito de blanqueo, ni se requiere sentencia condenatoria previa; resulta indispensable probar que con la ejecución de algunos delos verbos tipos descritos en el artículo 389 del Código Penal de 1982, interconectados con el delito predicado, lo pretendido por el sujeto activo del delito de blanqueo es el ocultamiento de dineros y bienes prevenientes de aquellos delitos; de lo contrario, se estaría condenando por la tenencia de dinero en grandes cantidades y con base en suposiciones y no en hechos que devienen de otros que son ciertos, lo que constituye prueba indiciaria; más no las inferencias o las suposiciones. Sobre este punto, nótese que no existen siquiera actuaciones instructivas tendientes a demostrar la posesión de bienes suntuosos, cuentas bancarias o dineros en tales cantidades que puedan relacionarse con la actividad ilícita de blanqueo de capitales, todo lo contrario, se comprobó en el caso de los señalados xxx, que los mismos son personas de un modesto modus vivendi (v.fs.354-357)....."

Por otra parte, tenemos que no solamente la jurisprudencia panameña establece que el delito de blanqueo de capitales requiere la existencia de evidencias previas sino que esta condición le hace ser un delito autónomo. Esto queda establecido en la sentencia fechada 27 de noviembre de 2014, misma que ha sido emitida por la Sala Segunda de lo Penal, de la Corte Suprema de Justicia, de la siguiente manera:

“......Esta máxima Corporación de Justicia, vía jurisprudencial, ha señalado que se trata de una conducta autónoma que no requiere que medie sentencia condenatoria por delito previo para que se constituya en un indicio contra el 


\section{sindicado; no obstante, sí se requiere de indicios que permitan deducir la existencia de un delito previo, de los consagrados en el artículo 389 del Código Penal de 1982."}

\section{Legislación Bancaria}

Panamá es un país con un gran movimiento financiero desde 1904 y no fue sino hasta el 2 de julio de 1970, que mediante Decreto de Gabinete $\mathrm{N}^{\circ} 238$, cuando se crea por primera vez una Ley Bancaria en nuestro país. Es así como surge la Comisión Bancaria Nacional y con posterioridad, la Superintendencia de Bancos de Panamá mediante el Decreto Ley 9 de 26 de febrero de 1998.

La Superintendencia de Bancos de Panamá cuenta con la Dirección de Prevención y Control de Operaciones Ilícitas, a través de la cual se realiza un monitoreo bancario como medida de prevención del blanqueo de capitales, financiamiento del terrorismo y de la proliferación de armas de destrucción masiva.

En Panamá, mediante Ley 23 de 27 de abril de 2015 se crea el Sistema de Coordinación Nacional para la Prevención del Blanqueo de Capitales, Financiamiento del Terrorismo y de la Proliferación de Armas de Destrucción Masiva de la República de Panamá, el cual está estructurado de la siguiente manera:

a. La Comisión Nacional contra el Blanqueo de Capitales, Financiamiento del Terrorismo y de la Proliferación de Armas de Destrucción Masiva, que a su vez está conformado por:

1. Ministerio de Economía y Finanzas

2. Ministerio de Relaciones Exteriores

3. Ministerio de la Presidencia

4. Superintendencia de Bancos de Panamá

5. Ministerio Público

6. Comisión de Economía y Finanzas de la Asamblea Nacional

b. La Unidad de Análisis Financiero para la Prevención del Delito de Blanqueo de Capitales y Financiamiento del Terrorismo

c. Organismos de Supervisión, que a su vez está integrado por:

1. Superintendencia de Bancos de Panamá

2. Superintendencia de Seguros y Reaseguros de Panamá

3. Superintendencia del Mercado de Valores

4. Intendencia de Supervisión y Regulación de Sujetos no Financieros

5. Instituto Panameño Autónomo Cooperativo

Además, contamos con las siguientes normativas jurídicas a nivel bancario:

a. El Texto Único del Decreto Ley $\mathrm{N}^{\circ} 9$ de 26 de febrero de 1998 y todas sus modificaciones.

b. Ley 23 del 27 de abril de 2015, que adopta medidas para prevenir el blanqueo de capitales, el financiamiento del terrorismo y el financiamiento de la proliferación de armas de destrucción masiva, y dicta otras disposiciones. (Modificada por la Ley 21 de 2017)

c. Decreto Ejecutivo $\mathrm{N}^{\circ} 363$ del 13 de agosto de 2015, que reglamenta la ley 23 del 27 de abril de 2015, que adopta medidas para prevenir el blanqueo de capitales, el 
financiamiento del terrorismo y el financiamiento de la proliferación de armas de destrucción masiva y dicta otras disposiciones.

d. Decreto Ejecutivo $\mathrm{N}^{\circ} 587$ de 4 de agosto de 2015, que reglamenta el congelamiento preventivo desarrollado en el Título VI de la Ley 23 de abril de 2015, mediante el cual se adoptan medidas para prevenir el blanqueo de capitales, el financiamiento del terrorismo y el financiamiento de la proliferación de armas de destrucción masiva y dicta otras disposiciones.

e. Decreto \# 55 de 1 de febrero de 2012, que modifica el Decreto Ejecutivo 1 de 3 de enero de 2001, que reglamenta la ley 42 de 2 de octubre de 2000

f. Decreto \# 855 de 24 de agosto de 2010, por el cual se designan a los representantes del sector privado ante la comisión presidencial de alto nivel contra el blanqueo de capitales y el financiamiento del terrorismo.

g. Decreto Ejecutivo \# 266 de 23 de marzo de 2010, que modifica el Decreto Ejecutivo \# 1 de 3 de enero de 2001, que reglamenta la Ley 42 de 2 de octubre de 2000.

h. Decreto Ejecutivo \# 195 de 18 de octubre de 2007, que establece el procedimiento para acatar las resoluciones emanadas del Consejo de Seguridad de las Naciones Unidas.

i. Decreto \# 76 de 26 de mayo de 2006, que hace algunas adiciones a los artículos 2 y 3 del Decreto Ejecutivo 125 de 27 de marzo de 1995 y se adoptan otras disposiciones.

j. Decreto \# 65 de 12 de septiembre de 2006, que reglamenta algunas disposiciones de la ley 16 de 23 de mayo de 2005 sobre las casas de empeño.

k. Decreto \# 136 de 9 de junio de 1995, mediante el cual se crea la Unidad de Análisis Financiero para la prevención del delito de lavado de dinero producto del narcotráfico, adscrita al Consejo de Seguridad Pública y Defensa Nacional.

1. Decreto \# 78 de 4 de junio de 2003, mediante el cual se crea la unidad de análisis financiero para la prevención del blanqueo de capitales y el financiamiento del terrorismo.

m. Ley 42 de 2000 que establece medidas para la prevención del delito de blanqueo de capitales. Dictada por la Asamblea Legislativa el 2 de octubre de 2000, presente en la Gaceta Oficial \# 24152 - A

n. La ley 2 de 2011 que regula las medidas para conocer al cliente para los agentes residentes en entidades jurídicas existentes de acuerdo con las leyes d lea República de Panamá, promulgada en la Gaceta Oficial \# 26713 - C.

Por último, en Panamá, contamos con Acuerdos de la Superintendencia de Bancos, entre los que podemos mencionar:

a. Acuerdo \# 010 - 2015 de 27 de julio de 2015, que regula la prevención del uso indebido de los servicios bancarios y fiduciarios. (modificado por el Acuerdo \# 0012017 de 14 de febrero de 2017)

b. Acuerdo \# 009-2015 de 27 de julio de 2015, que establece el procedimiento administrativo sancionatorio por posibles infracciones a las disposiciones en materia de prevención del blanqueo de capitales, financiamiento del terrorismo y financiamiento de la proliferación de armas de destrucción masiva aplicable a los sujetos obligados. (modificado por el Acuerdo $\mathrm{N}^{\circ} 003-2017$ de 25 de abril de 2017)

En síntesis, con la implementación de las diferentes formas de normativas jurídicas a nivel bancario que hemos mencionado en párrafos anteriores, Panamá, ha pretendido cumplir con los estándares internacionales solicitados como medidas de prevención del delito de blanqueo de capitales y sus delitos determinantes o subyacentes. Entre estas medidas podemos mencionar el conoce a tu cliente, darle seguimiento a los ingresos de dinero en las diferentes 
cuentas bancarias, establecer requisitos para la apertura de una cuenta bancaria, determinar requisitos para responder ante transacciones bancarias (préstamos de diferentes clases, etc.), pedirle al cliente explicación sobre sus ingresos y el movimiento de su dinero, entre otras cosas.

\section{Derecho Internacional}

Panamá mediante el artículo 4 de su Constitución Política adopta el Derecho Internacional, razón por la cual contamos con la Unidad de Análisis Financiero (UAF) que pertenece al Ministerio de la Presidencia y vinculada al Consejo de Seguridad, la cual se encarga de revisar la información proveniente de todas las transacciones financieras, en las cuales estén involucradas cualquier entidad crediticia o financiera del país. De esta manera, puede el Estado identificar y prevenir actividades ilícitas relacionadas con el blanqueo de capitales. Esta unidad a su vez, guarda relación con una entidad intergubernamental, en la cual intervienen varios países y organizaciones internacionales, como Naciones Unidas, que es identificada como GAFI (Grupo de Acción Financiera Internacional), que surge en 1989 como una estrategia de prevención y control del blanqueo de capitales.

Por último, tenemos que en nuestro país se han adoptado los siguientes instrumentos jurídicos internacionales:

a. Convención de las Naciones Unidas contra el tráfico ilícito de estupefacientes y sustancias sicotrópicas de 1988

b. Convención de las Naciones Unidas contra la Delincuencia Organizada Transnacional.

c. Declaración Política y Plan de Acción contra el Blanqueo de Dinero

d. Declaración Política y Plan de Acción Mundial de Nápoles contra la Delincuencia Transnacional Organizada.

\section{Perfil Criminológico del Sujeto Activo en el delito de blanqueo de capitales}

En cuanto al perfil criminológico del agente, en el delito de blanqueo de capitales o lavado de activos, he de mencionar que lo podemos considerar de cuello blanco, perteneciente a la delincuencia organizada, que a través de diferentes tipos de asociaciones ilícitas operan en los diferentes sectores de la sociedad, entre los cuales podemos mencionar: iglesia, clubes cívicos, administración de justicia, el sector empresarial, diferentes instituciones públicas (ministerios o secretarías), el poder ejecutivo (presidencia, vicepresidencia), la policía, diferentes gremios que conforman la sociedad civil, medios de comunicación, entre otros.

Dependiendo del origen circunstancial o estructural del delito de blanqueo de capitales, podemos identificar dentro de las características del sujeto activo las siguientes:

a. Pertenece o está conectado con los sectores de gran importancia y poderío de carácter político, social y económico

b. Forma parte de redes de poder a nivel nacional e internacional

c. Mantiene, por lo general, un bajo perfil a nivel social. Es decir, contribuye con las campañas y estrategias de prevención de este tipo de figuras delictivas

d. Tiene una formación académica que generalmente es de carácter formal

e. Ocupa cargos de relevancia a nivel del sector empresarial y bancario

f. Son personas carismáticas y con buena proyección al público 
g. Generalmente se dedican a realizar un gran número de donaciones y ayudas a los más necesitados, prefiriendo en ayudas: los niños, enfermos e iglesias.

En síntesis, podemos señalar que el sujeto activo en los delitos de blanqueo de capitales está conformado por personas que tienen una aceptación y buen nombre en la sociedad dentro de la cual se desenvuelven. Considerándoles personas que trabajan en beneficio de su comunidad.

\section{Consideraciones Finales}

Dentro de las consideraciones finales con respecto al delito de blanqueo de capitales, podemos indicar las siguientes:

a. Es un delito que refleja la realidad del desvalor en el cual se encuentra sumergida no solamente la sociedad que conforma a un Estado, sino, también, de la comunidad internacional de la cual forma parte.

b. Que muchas veces, esto sucede sobre todo con los llamados delitos transnacionales, surgen figuras delictivas que en principio pensamos que están garantizando la protección de intereses jurídicos de la sociedad en términos generales, pero en realidad están respondiendo a intereses de fuertes grupos de poder a nivel mundial, pero que se esconden en organizaciones internacionales no gubernamentales, como lo es Naciones Unidas, intentando simular con esto que ayudan a disminuir los niveles de delincuencia en términos generales.

c. Nuestros ordenamientos jurídicos internos deben responder, en principio, a la realidad de las necesidades de nuestros pueblos y en segundo lugar, se deberán cumplir compromisos como parte de una comunidad internacional, pero en la medida que no se vean afectados nuestros intereses internos de nación.

d. Requerimos con urgencia la existencia de una Política Criminal de Estado que responda las necesidades reales de prevención y represión del delito. Pero, para esto se requiere que el Estado se enfoque a programas que vayan más allá de la reforma o creación de nuevas leyes. Por ejemplo: creación de bolsas de empleos para personas de todos los sectores académicos y no académicos, de diferentes edades y experiencias laborales. El diseño y ejecución de programas de viviendas con diferentes planes de financiamiento; mejora en el sistema educativo, etc.

e. Programas de concienciación a nivel de país, que logren cambiar antiguos paradigmas de corrupción en los diferentes sectores que conforman la sociedad en un Estado.

\section{Referencias Bibliográficas}

A. Obras

1. SÁENZ, J. Compendio de Derecho Penal (Parte General). Ed. Jurídica Pujol, S.A. Panamá, 2015, t. pp. 264

2. SÁENZ, J. Compendio de Derecho Penal (Parte Especial). Ed. Jurídica Pujol, S.A. Panamá, 2017. 2t. pp. 536

3. EZAINE CH., A. Delitos Económicos. Perú. 2009

4. GONZÁLEZ, E. Delitos Económicos. 2016

5. VÁSQUEZ ABAD, J. Tratado de Economía. España. 2008

6. LÓPEZ BETANCOURT, E. Delitos en Particular II. México. 2000

B. DICCIONARIOS

1. EZAINE CH, A. Diccionario de Derecho Penal. Ediciones Jurídicas Lambayecanas. Perú. 2000

C. TEXTOS LEGALES 
1. Código Penal Panameño 1982

2. Código Penal Panameño 2007

3. Constitución Política de Panamá

4. Código Procesal Penal Panameño

5. Convención de las Naciones Unidas contra el tráfico ilícito de estupefacientes y sustancias sicotrópicas de 1988

6. Convención de las Naciones Unidas contra la Delincuencia Organizada Transnacional.

7. Declaración Política y Plan de Acción contra el Blanqueo de Dinero

8. Declaración Política y Plan de Acción Mundial de Nápoles contra la Delincuencia Transnacional Organizada.

D. JURISPRUDENCIA

1. Sentencia de 21 de septiembre de 2009, del Segundo Tribunal Superior del Primer Distrito Judicial, de Panamá

2. Sentencia de 27 de noviembre de 2014, de la Sala Segunda de lo Penal, de la Corte Suprema de Justicia, de Panamá.

E. INTERNET

1. www.doctorajuliasaenz.com

2. www.organojudicial.gob.pa

3. www.superintendenciadebancos.gob.pa

4. www.ministeriopublico.gob.pa

JULIA ELENA SÁENZ: Licenciada en Derecho y Ciencias Politicas, egresada de la Universidad de Panamá. Doctorado en Derecho Penal en la Universidad Nacional Autónoma de México (UNAM). Maestría en Derecho Penal en la Universidad de Guadalajara, México. Maestría en Docencia Superior en la Universidad de Panamá. Maestría en Investigación y Métodos de Evaluación Educativa en la Universidad de Panamá. Profesora de Segunda Enseñanza en la Universidad de la Paz. Catedrática en la Facultad de Derecho y Ciencias Políticas de la Universidad de Panamá. Correo electrónico: juliaelenasaenz@gmail.com

Artículo recibido: 9 de agosto de 2018

Aprobado: 23 de agosto de 2018 